\title{
La estela del rey Seankhiptah. Recientes investigaciones
}

Miguel JARAMAGO

Revisión de la Estela de Seankhiptah, del Museo Arqueológico Nacional, Madrid, considerando la estrecha relación que existe entre ella y la Estela C13 del Louvre. Dos conclusiones parecen derivar de esa comparación: Seankhiptah pudo ser el marido (o uno de ellos) de la reina Nubkhaes A; su reinado, por tanto, habría de ubicarse a mediados de la dinastía XIII y no a finales, como se sospechaba hasta ahora.

\section{The stela of Seankhiptah. Recent research}

Revision of the Stela of king Seankhiptah (Madrid, Museo Arqueológico Nacional) considering the narrow relationship that links this monument with Stela C13 of Louvre. Two conclusions arise: Seankhiptah was probably the husband (or one of them) of queen Nubkhaes A, and consequently, his reign would have taken place in the mid 13th dynasty and not at the end of it, as supposed so far.

KeY-words: $13^{\text {th }}$ Dynasty, Seankhiptah, Nubkhaes A, Museo Arqueológico Nacional

$\mathrm{E}$ 1 objeto de nuestra comunicación es la estela inventariada con el $\mathrm{n}^{0}$ de inventario 1999/99/4 del Museo Arqueológico Nacional de Madrid, que ha sido ya sujeto de varias investigaciones $^{1}$. Nuestro propósito inicial era de tipo cronológico, pues se trataba de fijar con mayor precisión la datación concreta del rey Seankhiptah, pero el proceso de estudio nos ha deparado interesantes sorpresas. Creemos que es posible no sólo delimitar con mayor precisión la cronología asignada al mencionado rey por otros investigadores, sino también conocer mejor su entorno histórico y hasta cierto punto vislumbrar las circunstancias en que el Egipto del comienzo del Segundo Periodo Intermedio vivió la disolución del poder central en manos de poderosas dinastías locales.

Una primera fase de investigación nos hizo contemplar la estela de manera intrínseca. Se trataba de conocer todo lo que la pieza nos podía aportar per se. La publicación de la misma

* Suum cuique: Agradezco a María del Carmen Pérez Díe - conservadora jefe de la Sección de Antigüedades de Egipto y Próximo Oriente del Museo Arqueológico Nacional y directora de la Misión Arqueológica Española en Heracleópolis Magna- la oportunidad que me brindó de trabajar sobre esta excelente pieza; a la investigadora Elisa Castel su ayuda técnica en la elaboración de los soportes informáticos de la comunicación; y al investigador Juan Rodríguez Lázaro, con quien he tenido ocasión de discutir en numerosas ocasiones distintos aspectos de la estela, el jugoso intercambio de puntos de vista. A todos ellos mi agradecimiento. En cualquier caso, sólo quien suscribe es responsable de las líneas que a continuación se extienden.

1. Entre otras: Jaramago, 2003; Rodríguez Lázaro, 2004a y 2004b.

Fecha de recepción: 12 de enero de 2007

Fecha de admisión: 15 de mayo de 2007 
nos permitió dar a conocer que su epigrafía ofrecía interesantes peculiaridades, entre las cuales destacaba la aparición de particularidades del neoegipcio en la semántica o la singular (y novedosa) grafía de ciertos signos ${ }^{2}$. Pero lo más interesante era que la estela hacía contemporáneos a dos personajes egipcios: el rey Sehekaenra Seankhiptah y al Canciller del Bajo Egipto Nebsumenu. Esta relación directa entre ambos personajes se producía a través de un pasaje textual (las tres líneas finales de texto), en el que se dice que ciertas tierras cultivables que eran propiedad del mencionado Canciller pasaban a tener un status distinto, pasaban a ser "distritos". Este hecho tenía lugar en el Año 1 del reinado de Seankhiptah, y aparecía recogido (ratificado, por tanto) en la estela que comentamos.

Entre las tierras que al parecer formaban parte del lote de Nebsumenu (o que eran limítrofes con ellas) el texto recoge de manera explícita una mención de la que denomina tierra de Hemu y que en su día interpretamos, erróneamente, como una alusión a una tierra navegable ${ }^{3}$ (cf. infra nuestra interpretación actual).

La segunda fase de la investigación nos ha hecho contemplar la pieza de forma extrínseca. Desde este punto de vista ya habíamos reconocido paralelos epigráficos en la grafía de algunos de los signos, así como paralelos iconográficos en otras estelas del periodo. Sin embargo, un documento que no habíamos tenido aún en cuenta [10] en trabajos previos nos ha sido de excepcional ayuda a la hora de entender y contextualizar correctamente la estela de Madrid. Se trata de la Estela C13 del Museo del Louvre, elaborada bajo el reinado de Nubkhaes A, reina de la dinas-

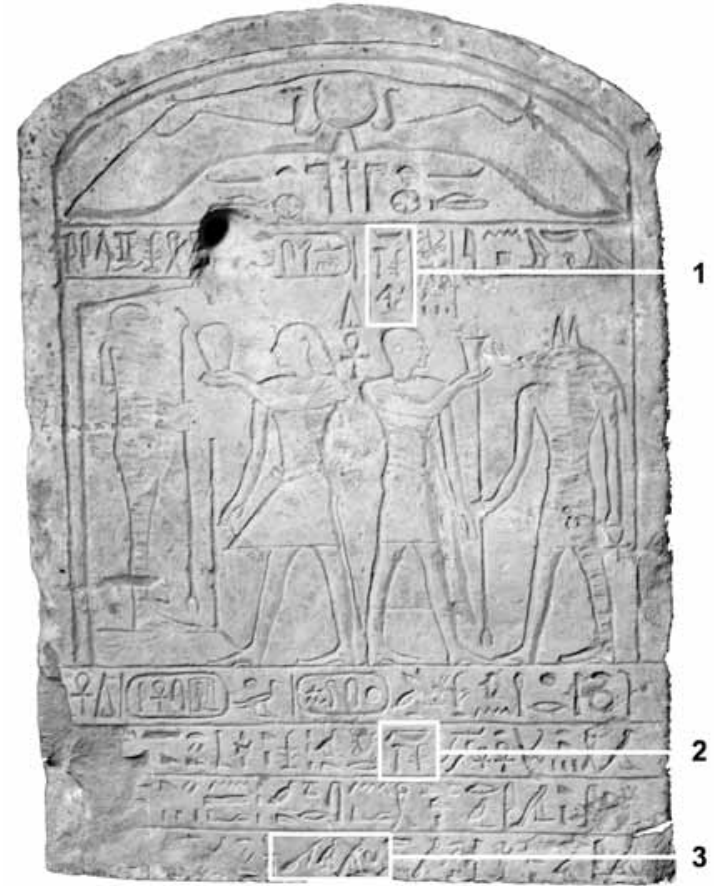

Figura 1. Estela de Seankhiptah 1: Nebsumenu

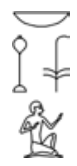

2: $<$ Neb $>$ sumenu, corrigiendo la ausencia de nb en el texto de la estela

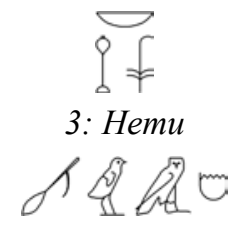

tía XIII ${ }^{4}$. En el texto se recoge, entre otras cosas, de forma pormenorizada, la genealogía completa de la mencionada reina (desde sus abuelos a sus descendientes directos ${ }^{5}$ ) sin mencionar al rey, su

2. Jaramago, 2003: 108-110.

3. Jaramago, 2003: 108.

4. La bibliografía esencial de la estela C13 está recogida en Malaise, 1981: 282. La denominación Nubkhaes A se usa en Dodson y Milton, 2004: 107 y 111, a fin de distinguir esta reina de su homónima de la XVII dinastía.

5. La bibliografía sobre esta familia es abundante. Véase Spalinger, 1980 y Ryholt, 1997: 239-242. 


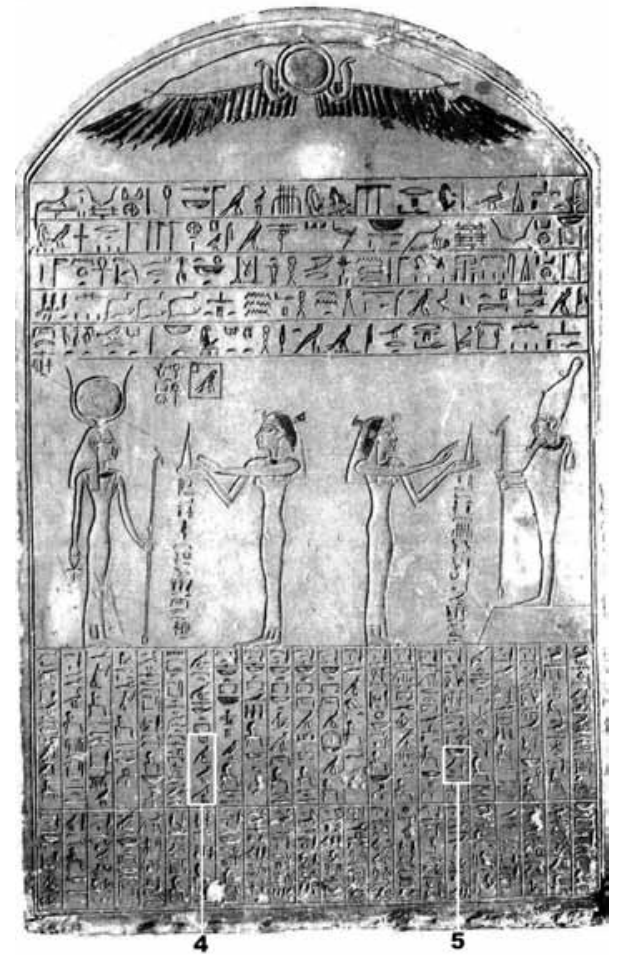

Figura 2. Estela de Nubkhaes 4: Нети

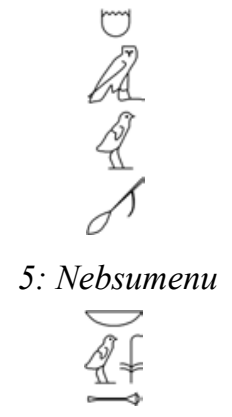

esposo. Esta ausencia es aún más inexplicable si tenemos en cuenta que es a él a quien debe su título real, ya que Nubkhaes A no desciende de reyes y, por tanto, fue reina por haberse casado con un hombre que era o se convirtió en el monarca. De hecho, el marido de Nubkhaes A nos era desconocido hasta la fecha, pues ningún documento del reinado de Nubkhaes A recoge su nombre, por lo que se había especulado con varios soberanos a partir de informaciones indirectas, procedentes principalmente del tío de la reina y de una de sus hijas ${ }^{6}$.

La mencionada estela C13 de El Louvre ofrece, en la genealogía de la reina, el nombre de uno de sus hermanos, Nebsumenu, que fue Canciller del Bajo Egipto7. La noticia por sí sola nos habría alertado acerca del Canciller mencionado en la estela de Madrid. Pero es que, además, la misma estela C13 de El Louvre recoge el nombre de la abuela materna de la reina Nubkhaes A, la señora de la casa Hemu ${ }^{8}$. Esto permite entender, en la estela de Madrid, el término de la última línea, la tierra de Hemu, como un topónimo construido mediante genitivo indirecto a partir de un nombre propio ${ }^{9}$, el nombre de la abuela materna de la reina Nubkhaes A.

En este momento de la investigación las informaciones de ambas piezas parecen complementarse maravillosamente: en la Estela de Madrid aparece reflejado uno de los hermanos de la reina Nubkhaes A, que fue Canciller del Bajo Egipto, Nebsumenu, quien, por mediación regia, modifica el status de sus tierras, como ya hemos comentado. Entre las propiedades del mencionado Canciller, o tal vez lindando con ellas, estaba la tierra de Hemu, un lote que

6. Mientras que ciertos investigadores han evitado pronunciarse acerca del nombre del marido de la reina Nubkhaes A (por ejemplo Ryholt, 1997: 242), otros han dudado entre los monarcas Sobekhotep V, Sobekhotep VI e Ibiaw (Spalinger, 1980: 114 y ss; Dodson y Milton, 2004: 107; Troy, 1986: 160).

7. Spalinger (1980: 97) menciona el segundo título de Nebsumenu (un cargo de escriba regio), que aparece en la Estela Louvre C13 a continuación del primer título (Canciller del Bajo Egipto). Por cierto, la reina Nubkhaes A tuvo otro familiar que desempeñó este cargo: su tío paterno Nebankh.

8. Sobre esta dama Hemu, véase Newberry, 1929: 76 y Weill, 1932: 16-17. La grafía del nombre es, además, coincidente en ambas estelas (Madrid y Louvre); se trata de la recogida en Ranke, 1935-77: I, 240 (segunda modalidad).

9. Ejemplos de topónimos que siguen esta construcción, recogidos en Gauthier, 1921-1931: VI, 19, 24. 
se denominaba así por su propietaria (que no fue sino la abuela materna de Nubkhaes A y de su hermano Nebsumenu), la dama Hemu. El aire de familia que impregna ambos textos, complementarios como vemos, nos conduce a la primera de nuestras conclusiones: el hasta ahora desconocido marido de la reina $\mathrm{Nu}-$ bkhaes A no fue sino Sehekaenra Seankhiptah ya que, como demuestra la estela del Museo Arqueológico Nacional, el hermano de la reina Nubkhaes A, el Canciller del Bajo Egipto Nebsumenu, fue contemporáneo de este monarca (cuadro 1). O, al menos, éste fue uno de sus maridos (pues desconocemos si tuvo otros). El presumiblemente corto reinado de Seankhiptah (el único documento seguro que es atribuible a este monarca -la estela de Madrid- hace referencia a su año 1) tal vez fuera la causa de que Nubkhaes A no mencionara el nombre de su marido en ninguno de los otros documentos que conocemos de ella.

Una segunda conclusión, de orden cronológico, nos lleva a situar a Seankhiptah en el grupo de Sobekhotep V, Sobekhotep VI e Ibiaw, ya que precisamente en el entorno de estos reyes es donde se había buscado al marido de Nubkhaes A, siempre usando los investigadores evidencia indirecta (el tío de la reina, Nebankh, y la familia de la princesa Khonsu) ${ }^{10}$. Por tanto, Seankhiptah no reinó al final de la dinastía XIII, como se ha mantenido recientemente ${ }^{11}$, aunque sí en la segunda mitad de la misma.

[12 ]

Una reina que no procede de la familia real y que oculta el nombre de su marido en una genealogía oficial, un monarca de breve reinado, una recalificación de tierras (forzada mediante documento regio: la estela de Madrid) ... todo esto no hace sino avalar la tesis de la debilidad del poder real, y el apoyo de los monarcas (en ocasiones mediante matrimonio) en grandes familias poseedoras de tierras. Sin duda estamos constatando factores de crisis que permiten hablar no ya de final del Reino Medio, sino del Segundo Periodo Intermedio.

\section{Discusión en el Congreso}

La presentación pública de esta comunicación durante el III Congreso de Egiptología Ibérica suscitó la cuestión de la autenticidad de la estela de Seankhiptah. Dedicamos así algunas líneas a resumir la argumentación cruzada que hubo sobre el tema.

\section{Argumentos epigráficos}

A. Diego Espinel preguntó si la grafía particular de la $h$ (signo V28 de Gardiner) podría ser considerada evidencia de falsificación. Nuestra respuesta es que no es necesariamente así: un buen número de lapicidas egipcios usó esta peculiar grafía, como numerosos comparanda demues$\operatorname{tran}^{12}$.

\section{Argumentos literarios}

J. M. Galán Allué señalaba que el texto de la estela recuerda el de las estelas de donación, pero ésta no es una de ellas. En efecto, no es una estela de donación: recuerda a este tipo de estelas, entre otras cosas, en la mención de los límites de las tierras mediante la referencia a los puntos cardinales, y en el uso reiterado de la $m$ de predicación. Pero esta estela tiene otro carácter; recoge una recalificación de tierras, en un momento histórico especialmente delicado (hemos aludido a la debilidad del poder regio). Se trata de un documento de otro tipo.
10. Spalinger, 1980: 114 y ss.

11. Ryholt, 1997: 73.

12. Ya nos referimos a ello in extenso en Jaramago, 2003. 


\section{Cuadro 1}

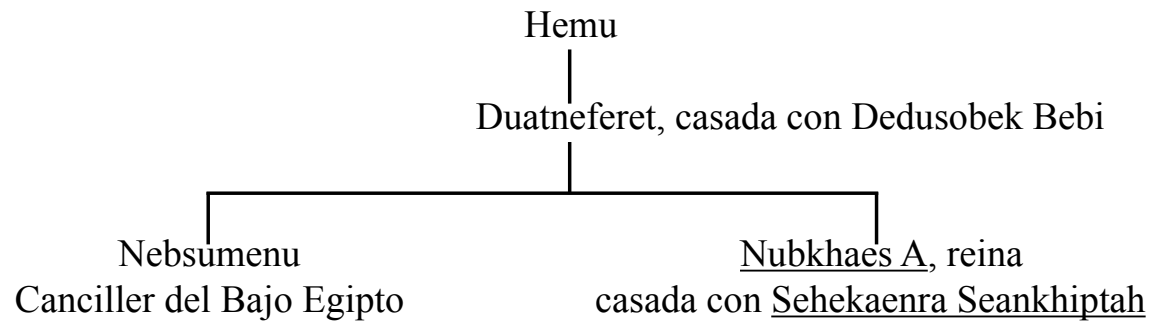

\section{Argumentos iconográficos}

J. M. Galán Allué se interesaba por la disposición poco convencional de los personajes, pues el rey y su Canciller se dan la espalda. Como respuesta hay que señalar que en el SPI se documentan paralelos con esta misma disposición de los personajes en la estela ${ }^{13}$. Incluso el canon de proporciones usado por el artista se ajusta admirablemente al imperante en el periodo ${ }^{14}$, así como ciertos detalles iconográficos (su indumentaria, la manera de realizar el nemes o el suave, casi sugerido más que trazado, uraeus regio) que son muy característicos del arte de este periodo ${ }^{15}$. Evidentemente no es una pieza de gran calidad artística, pero las circunstancias que vive la corte en este momento permiten entender esto. También J. M. Galán Allué se sorprendía por el hecho de que Nebsumenu aparezca ante Anubis en una pieza como esta. Según ha comentado Rodríguez Lázaro (haciéndose eco de un trabajo de Sauneron), existe una estrecha relación entre los tesoreros ${ }^{16}$ y los embalsamadores ${ }^{17}$.
Probablemente a esto alude la representación de Nebsumenu ante un Anubis que es denominado precisamente "señor de los embalsamadores" en el texto.

\section{Argumentos relativos a su estado físico}

Por último, J. M. Galán Allué pedía alguna aclaración sobre la evidente manipulación de la que había sido objeto la estela en varias de sus caras (inferior, trasera), y el pulido al que se habían sometido estos lados. En efecto, se ha realizado dicha operación, pero se trata de un pulido realizado en época moderna sobre la pátina antigua (que, por tanto, se ha perdido en estas zonas). Quizás buscando un mejor apoyo de la pieza, los propios tratantes de antigüedades han erosionado en fechas recientes la caliza original. Algún autor ha pensado incluso que el texto de la base de la estela de Madrid está incompleto, por una hipotética pérdida de líneas en la zona inferior ${ }^{18}$. En cualquier caso, se trata de un manipulado moderno sobre una

13. La Estela Louvre C13 es precisamente un ejemplo de este tipo. Otro ejemplo, recogido en Rodríguez Lázaro, 2004a: 168, del reinado de Sobekhotep III. Los personajes centrales (dos imágenes del rey, en los dos casos) se dan la espalda, para dar culto a las divinidades, que ocupan los lados exteriores del campo iconográfico de la estela.

14. Jaramago, 2003: 109.

15. Rodríguez Lázaro, 2004a: 157

16. Rodríguez Lázaro (2004a) traduce el título de Nebsumenu en la estela de Madrid como "Tesorero Real"; nosotros hemos mantenido la traducción tradicional, "Canciller del Bajo Egipto". Pero ambos hacen referencia al mismo título.

17. Rodríguez Lázaro, 2004a: 163-164 y nota 16. 
pieza antigua pues, de hecho, sí hay pátina antigua en el resto del monumento.

Creemos, en fin, que resulta inverosímil pensar en una falsificación tan erudita que incluya, entre otras cosas, formas de neoegipcio junto a un topónimo formado a partir del nombre de la abuela materna de la reina $\mathrm{Nu}-$ bkhaes A. Recordemos, por último, que recientemente tanto Ryholt como von Beckerath han considerado auténtica la pieza de forma indirecta, pues han recogido de la misma (para sus respectivas obras ${ }^{19}$ ) los dos cartouches de Seankhiptah. Junto a estos dos autores, la reciente inclusión de la estela de Seankhiptah en la Topographical Bibliography ${ }^{20}$, sin objeciones de ningún tipo en cuanto a su autenticidad, y aceptando las lecturas que hemos propuesto tanto para el nombre del rey (Sankhiptah, en versión de esta publicación británica) como para el de su Canciller (Nebsumenu) respaldaría la aceptación de la autenticidad por el equipo de egiptólogos que elabora el mencionado trabajo.

20. Malek, Porter y Moss, 2007: 6, pieza número 803-039-320, en el apartado "Stelae mentioning land or property"; http:// griffith.ashmus.ox.ac.uk/gri/8ste350.pdf, consulta efectuada en enero de 2007. 


\section{Bibliografía}

BeCKerath, J. Von

1999 Handbuch der ägyptischen Königsnamen. Mainz.

Dodson, A.; Milton, D.

2004 The Complete Royal Families of Ancient Egypt. London.

GAUTHIER, H.

1921-1931 Dictionnaire des noms géographiques contenus dans les textes hiéroglyphiques. Vols. I-VII. El Cairo.

Jaramago, M.

2003 The Stela of Seankhiptah in Madrid. An epigraphical analysis, $T d E$ 2: 99-112.

Malaise, M.

1981 Inventaire des steles égyptiennes du Moyen Empire porteuses de représentations divines, SAK 9: 259-283.

Malek, J.; Porter, B.; Moss, R. L. B.

2007 Topographical bibliography of ancient Egyptian hieroglyphic texts, reliefs, and paintings 8. Objects of Provenance Not Known. 3: Stelae (Early Dynastic Period to Dynasty XVII). Oxford.

NEWBERry, P.

1929 The base of a Statuette of the Lady DuatNefert, mother of Queen Nubkhaes, $A S A E$ 29: 76 .
RANKE, $\mathrm{H}$.

1935-77 Die ägyptischen Personenamen. Glücsktadt, 3 vols.

RoDríGUEz LÁzARO, J.

2004a La Estela del Tesorero real Nebsumenu, Boletín de la Asociación Española de Orientalistas 40: 149-172.

2004b Seheqaenre Seankhptahi, un oscuro rey de la XIII dinastía en el Museo Arqueológico Nacional de Madrid, Boletín Informativo de Amigos de la Egiptología XVII: 3-5.

RYHoLt, K.

1997 The Political Situation in Egypt during the Second Intermediate Period c.1800-1550 $B C$. Copenhague.

\section{Spalinger, A.}

1980 Remarks on the family of Queen Ha.s-nbw and the problem of kingship in Dynasty XIII, $R d E$ 32: 95-116.

TROY, L.

1986 Patterns of Queenship in ancient Egyptian myth and history. Uppsala.

WeILL, R.

1932 Complément pour "la fin du Moyen Empire égyptien". Monuments et faites documentaires, BIFAO 32: 7-52. 


\section{Trabajos de Egiptología Papers on Ancient Egypt}

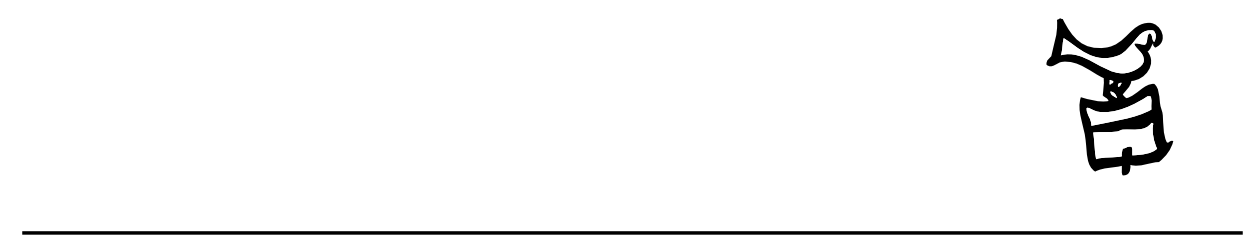

Número 5/2 2009 


\section{Actas \\ III Congreso Ibérico de Egiptología III Congresso Ibérico de Egiptologia}

Editores

Miguel Ángel Molinero Polo Covadonga Sevilla Cueva 


\title{
Editor
}

Miguel Ángel Molinero Polo

Universidad de La Laguna

\section{Consejo Editorial}

\author{
Antonio Pérez Largacha \\ Universidad de Castilla-La Mancha \\ José-R. Pérez-Accino \\ Birkbeck, Universidad de Londres \\ Covadonga Sevilla Cueva \\ Universidad Autónoma de Madrid
}

\section{Comité Científico}

Josep Cervelló i Autuori

Universitat Autònoma de Barcelona

$\mathrm{M}^{\mathrm{a}}$ José lópez Grande

Universidad Autónoma de Madrid

Josep Padró i Parcerisa

Universitat de Barcelona

$\mathrm{M}^{\mathrm{a}}$ Carmen Pérez Die

Museo Arqueológico Nacional, Madrid

Ester Pons Mellado

Museo Arqueológico Nacional, Madrid

José M. Serrano Delgado

Universidad de Sevilla

\section{Colaboradores Editoriales}

Linda Steynor

English editorial assistant

Hervé Mouriacoux

Assistant éditorial pour la langue française 
Trabajos de Egiptología está producida por Isfet. Egiptología e Historia c/ Blanco $1,2^{\circ}$

38400 Puerto de la Cruz

Tenerife-Islas Canarias

España

Maquetación: Proyecto Limón

(C) Autores de los artículos aparecidos

y Consejo Editorial de Trabajos de Egiptología - Papers on ancient Egypt

Depósito Legal: TF-2303-2009

ISSN: $1695-4750$

Imprime: Gráfica Los Majuelos, S.L.L.

imprenta@graficaslosmajuelos.com

Tfno.: 922311455 


\section{Comité Científico \\ III Congreso Ibérico de Egiptología III Congresso Ibérico de Egiptologia}

Miguel Á. Molinero Polo

Universidad de La Laguna

Presidente del Comité Organizador del III Congreso Ibérico de Egiptología

Miembro del Comité Organizador del I Encuentro de Egiptología

Josep Cervelló Autuori

Universitat Autònoma de Barcelona

Presidente del Comité Organizador del II Congreso Ibérico de Egiptologia

José Manuel Galán Allué

Consejo Superior de Investigaciones Cientificas

Director del Proyecto Djehuty, Luxor, Egipto

$\mathrm{M}^{\mathrm{a}}$ Helena Trindade Lopes

Universidad de Lisboa

Directora de la Misión Arqueológica Portuguesa en Menfis

Josep Padró i Parcerisa

Universitat de Barcelona

Director de la Misión Arqueológica de Oxirrinco

Antonio Pérez Largacha

Universidad de Castilla - La Mancha

Miembro del Comité Organizador del I Encuentro de Egiptología

José Ramón Pérez-Accino

Birkbeck College, University of London

Miembro del Comité Organizador del I Encuentro de Egiptología

$\mathrm{M}^{\mathrm{a}}$. Carmen Pérez Díe

Museo Arqueológico Nacional

Directora de la Misión Arqueológica Española en Heracleópolis Magna, Egipto

Covadonga Sevilla Cueva

Universidad Autónoma de Madrid

Miembro del Comité Organizador del I Encuentro de Egiptología 